\title{
Saudi Women's Attitudes toward Physical Activity: An Interventional Approach to Improving Future Health
}

\author{
Ahmed Abdulrahman Al-Haramlah ${ }^{1}$, Haniah Merza ${ }^{2} \&$ Fawziah Albakr ${ }^{3}$ \\ ${ }^{1}$ Assistant Professor of Applied Sport Psychology, Northern Border University, Saudi Arabia (K.S.A.), Rep. of \\ the (K.S.A.) in (ASPASP), Asian-South Pacific Association of Sport Psychology, Saudi Arabia \\ ${ }^{2}$ Consultant of College of Education, Director of Support Center and Accessibility Program, Princess Norah \\ University, Saudi Arabia \\ ${ }^{3}$ Sociology of Education, Department of Educational Policy, King Saud University, Saudi Arabia \\ Correspondence: Ahmed Abdulrahman Al-Haramlah, Assistant Professor of Applied Sport Psychology, Northern \\ Border University, Saudi Arabia, (K.S.A.), Rep. of the (K.S.A.) in (ASPASP), Asian-South Pacific Association \\ of Sport Psychology, Saudi Arabia. E-mail: Ahmad_Alharamlah@yahoo.com; Ahmed.Alharamlah@nbu.edu.sa.
}

Received: January 20, 2016 Accepted: March 23, 2016 Online Published: June 21, 2016

doi:10.5539/ass.v12n7p95 URL: http://dx.doi.org/10.5539/ass.v12n7p95

\begin{abstract}
The aim of this research was to provide evidence to support physical activity initiatives that improve the quality of life of women in Saudi Arabia. Research on Saudi women correlates higher incidence of obesity, diabetes, hypercholesterolemia, and osteoporosis to the lack of exercise in Saudi women's lifestyle. Hence, this study uses an interventional approach to support efforts that encourage physical activity in Saudi women. A pilot sample of 80 females was interviewed to secure the validity and reliability of the preliminary instrument. The final version of the instrument, consists of (63) items, was distributed to a sample consists of 1233 females aged 15 and up from four main regions in KSA. The results indicate that awareness and positive attitudes toward physical activity exist. Improvement of quality of life can be as simple as lessening the practical impediments. Hopefully, this kind of evidence can better inform decision makers to be more proactive in providing government funded facilities.
\end{abstract}

Keywords: physical activity, women, KSA

\section{Introduction}

One of the most important variables that deemed as risk factors was physical inactivity, with which numerous chronic diseases were related i.e., chronic heart disease, diabetes mellitus II, obesity and hypertension (Al-Nozha et al., 2007). Physical inactivity among females was related to different factors such as poverty or socioeconomic group, low level of education, technological changes result in sedentary behaviours, lack of social support, lack of time, parental demands, limited access to services, body image, and health conditions (Gómez et al., 2004 and Women's Health Victoria, 2010). For Arab countries, statistics show a lack of physical activity between adults range from $33 \%$ to $86 \%$ in seven countries, namely, Egypt, Iraq, Jordan, Kuwait, Saudi Arabia, Sudan, and Syria (Regional Office of World Health Organization, Cairo). In Gulf States, the percentage of obesity was ranged from 8 to $9 \%$ among children before school age (The University Center for Obesity Research, 2010). As for Saudi society, local research show that obesity and diabetes had spread across all age groups. Statistics show that $28 \%$ of citizens are suffering from obesity, accordingly threatening around 4 million Saudi citizens, including $4 \%$ of children with obesity percentage reaching $35 \%$, and $40 \%$ for adults. According to reports from the World Federation of Diabetes, the Kingdom ranks second worldwide in obesity (University Center for Obesity Research, 2012). Al-Eisa and Al-Sobayel (2012) conducted a study in order to explore the level of physical activity among Saudi females. Their findings pointed out a low level of physical activity among participants.

Perhaps one of the facts unknown to many people is the historical stages that women's sports went through in Saudi society where some studies show the time when women's sports began was 1966 (Al-Bakr, 2003; Al-Maena, 2013). This initiative included a limited number of private schools, for example, Dar Al-Hanan School in Jeddah, in addition to a few women private sports clubs in the western province. However, after the second gulf war and the Salafi movement, which extended to educational institutions, the decision of total 
prohibition of women's practicing of physical activities was enforced in these facilities, accordingly, these facilities were totally closed (Addosari, 2011; Al-Eesa, 2011; Al-Khodr, 2010). Consequently, all women formal participation in physical activities became forbidden (Al-Jebro'o and Al-Mohaisn, 2011; Al-Baker, Al-Haramlah, \& Mreza, 2013; Al-Haramlah, Al-Bakr, \& Merza, 2015; Al-Baker, Al-Haramlah, \& Mreza, 2016). It is apparent that the ban of women participation in sports is based on the hesitance of institutions that have authority to make such decision; or the activation of royal decree number (7/ B/ 36132) in 22/9/2003 which stated the agreement of ministry council approval to undertake a study by the General Presidency of Youth Welfare to summon its feasible contribution to women physical activities within Islamic boundaries. But it appears according to Al-Jebro'o and Al-Mohaisn (2011), the reason of not enforcing the decision by authorities is the social and intellectual barrier of the society. Hence, the aim of this study is to investigate the level of physical activity among Saudi women and to explore differences in terms of factors such as place of residence, age, weight, educational level, profession and marital status.

\section{Study Questions and Hypotheses}

The present study is driven by two main questions: what are the attitudes of Saudi women towards practicing physical activities? And, are there any significant statistical differences in Saudi women's attitudes towards practicing physical activities that are based on the provinces of residents, age group, weight, educational level, nature of profession or marital status?. Consequently, six hypotheses were drawn: there are no significant statistical differences at $\alpha \leq 0.05$ in the attitudes of Saudi women's towards practicing physical activities based on the province residence, there are no significant statistical differences at $\alpha \leq 0.05$ in the attitudes of Saudi women's towards practicing physical activities based on age group, there are no significant statistical differences at $\alpha \leq 0.05$ in Saudi women's attitudes towards practicing physical activities based on weight, there are no significant statistical differences at $\alpha \leq 0.05$ in Saudi women's attitudes towards practicing physical activities based on the educational level, there are no significant statistical differences at $\alpha \leq 0.05$ in Saudi women's attitudes towards practicing physical activities based on the nature of profession. Finally, there are no significant statistical differences at $\alpha \leq 0.05$ in Saudi women's attitudes towards practicing physical activities based on marital status.

\section{Methodology}

The research team chose to employ the descriptive analytical method in order to achieve the study goals by reviewing the literature and previous studies that dealt with Saudi women's attitudes towards practicing physical activities. The team has developed a questionnaire to achieve the objectives of the study by collecting the required data, then analyzing it and answering the questions to infer the results and present a set of recommendations based on these results.

\subsection{Participants}

The study population consisted of all Saudi women at the level of all major geographic provinces in Saudi Arabia; and because of difficulties in counting the original population; the researcher limited the study to include employed and un-employed women and female students in the educational institutions over all provinces. The researchers included a random sample of 1500 women that represent the characteristic of the population. The questionnaire was distributed by hand and via email. Out of the distributed questionnaires, 1327 questionnaires were returned and 94 questionnaires were excluded due to incompleteness and insatiability for the statistical analysis. The total number of questionnaire used was 1233 questionnaires. Table 1 shows the characteristics of the selected sample.

Table 1. Sample characteristics

\begin{tabular}{cccc}
\hline The Variable & Variable Category & Sample & Percentage \\
\hline \multirow{3}{*}{ Residents } & Central Province & 772 & 62.6 \\
& Eastern Province & 65 & 5.30 \\
& Western Province & 95 & 7.70 \\
& Northern Province & 46 & 3.70 \\
& Southern Province & 255 & 20.7 \\
Age & $18-25$ & 892 & 72.3 \\
& $26-33$ & 155 & 8.40 \\
& $34-41$ & 65 & 5.30 \\
\end{tabular}




\begin{tabular}{cccc}
\hline The Variable & Variable Category & Sample & Percentage \\
\hline \multirow{3}{*}{ Approximate weight in kg } & $45-50$ & 303 & 24.6 \\
& $51-56$ & 265 & 21.5 \\
& $57-62$ & 222 & 18.0 \\
& $63-68$ & 144 & 11.7 \\
& $69-74$ & 112 & 9.10 \\
& $75-79$ & 141 & 11.4 \\
& 80 and over & 46 & 3.70 \\
Educational level & not educated & 6 & 0.50 \\
& read and doesn't write & 14 & 1.10 \\
& primary & 21 & 1.70 \\
& intermediate & 3 & 0.20 \\
& secondary & 187 & 15.2 \\
& Bachelor & 971 & 78.8 \\
& Master & 29 & 2.40 \\
& Ph.D. & 2 & 0.20 \\
& housewife & 70 & 5.70 \\
& teacher & 283 & 23.0 \\
& administrator & 82 & 6.70 \\
& professional & 49 & 4.00 \\
& Business woman & 7 & 0.60 \\
& other & 742 & 60.2 \\
& single & 739 & 59.9 \\
& married & 448 & 36.3 \\
& divorced & 40 & 3.20 \\
& widow & 6 & 0.50 \\
\hline
\end{tabular}

\subsection{Instrument}

The research team developed a questionnaire for measuring Saudi women's attitudes towards practicing physical activities based on literature review and group of previous studies that discuss various aspect of practicing physical activities. The goal is to explore employed tools in this research such as in Abd Al-A'ati (2011), Kana'an (2010), and Al-Khadoori (2010). In order to verify the validity and the stability of the tool, the questionnaire initially included 77 items, so that the researchers held personal interviews with an exploratory sample consisting of 85 Saudi women which represent the original population of the study. Therefore, the final version to the study tool of the questionnaire included two parts after validation: The research team devoted the first part to collect the demographic data of the sample, while the second part devoted to assist Saudi women attitudes towards practicing physical activities and contain 29 items in addition to one open question. The researchers have used Liker Scale to analyze the questionnaires answers and classify them to determine the weight of the items as follows: "always" represents 5 points, "often" represents 4 points, "sometimes" represents 3 grades, "rarely" represents 2 grades, and "never" represents 1 point. With respect to determining Saudi women's attitudes towards practicing physical activities, the research team depended on Likert Scale to, considering that 3 represents a neutral point "no attitude" according on Likerts's five-points scale. While moving away from this grade reflects the tendency type; so one point distant away from the neutral point by "1, 2" reflects negative tendency, while, two points distant away from the neutral point by " 4,5 " reflects positive tendency. Accordingly, evaluating the tendency according to this scale is considered a positive one if the mean of attitudes of the sample was above 3 , but if the mean was less than 3 points then the tendency will be considered a negative one.

\subsection{Validity and Reliability}

The draft version of the questionnaire was delivered to seven professionals in educational and sports psychology from four Saudi universities, namely King Saud University, Qassim University, King Saud University, and the University of Northern Border. The goal was to validate the items of the questionnaire in assign Saudi women's attitudes towards practicing physical activities, and to limit their focus to suggestions pertaining to requirements in sport clubs. Also to validate and make sure of the questionnaire cover the different domains. The team 
considered the validation of the valuators' suggestion, and rewards some items accordingly. The researchers relied on Cronbach's alpha formula to determine the coefficient of internal consistency of the questionnaire; these coefficients were high for the questionnaire as a whole and all of its items $(\alpha=0.80)$

\subsection{Statistical Analysis}

In order to answer the study questions, the researchers employed the Statistical Package for Social Science SPSS, was used as follows: the repetitions and percentages to recognize the characteristics of the study sample, the averages and the standard deviations to answer the first two questions, analysis of variance (ANOVA), Scheffe test for the post testing comparisons to test the hypotheses of the study.

\section{The Study Results}

In order to answer the first question, means and the standard deviations of Saudi women attitudes towards practicing physical activities was extracted, and the overall average for all items that showed positive attitude (Mean=3.75, standard deviation= 0.422 ). It seems that Saudi women in general would like to practice physical activities if they had the opportunity and suitable place. Table 2 shows means, standard deviations and tendency of attitudes scale items.

Table 2. The sample justifications for participation in physical activities

\begin{tabular}{lccc}
\hline Items & Mean & SD & Tendency \\
\hline I believe physical activities help maintain human health & 4.65 & .7970 & positive \\
Physical activities help maintain consistency and beauty of woman's body & 4.65 & .7160 & positive \\
I encourage physical activities for women within the social and religious & 4.58 & .7910 & positive \\
framework of the society & 4.43 & .8820 & positive \\
I prefer physical activities that maintain fitness & 4.42 & .9410 & positive \\
The main goal of practicing sports is to acquire health and fitness & 4.37 & .9940 & positive \\
I prefer physical activities that do not involve risk & 4.35 & .8450 & positive \\
Sports contribute to revive one's desire for life & 4.34 & .8800 & positive \\
Sport contributes to revive women's intellectual activities & &
\end{tabular}

Table 2 shows that Saudi women believe that practicing physical activities maintain human health and achieve their body fitness and beauty, this item come first with a mean of 4.65 and standard deviation of 0.716 respectively. The second item was "encouraging the idea practicing physical activities for women within the social and religious boundaries", the mean; is 4.58 and standard deviation is 0.791 . This is the same as the means with following averages confirm, such as maintaining body fitness with a mean of 4.43 ; and with the same strength, Saudi women saw that sport contributes to reviving women's intellectual activities with mean of 4.43, which reflects the high level of Saudi women's knowledge about the effective role of practicing physical activities within the field of physical, psychological and mental health, while observing the social boundaries that fit the woman and give her the required privacy for practicing such activities.

Table 3. Woman's tendency towards incorporating sports in schools and public clubs

\begin{tabular}{lccc}
\hline Items & Mean & SD & Tendency \\
\hline I prefer physical activities that maintain fitness & 4.43 & .8820 & positive \\
Sport activities are a healthy way to reduce psychological disorder & 4.30 & .8650 & positive \\
I consider incorporating physical activities that contain health benefits within the & 4.30 & 1.039 & positive \\
educational curriculum to be very important & & & \\
I would practice sports activity if a women's club membership becomes available & 4.29 & 1.055 & positive \\
Physical activities provide a chance to relax & 4.14 & .9900 & positive \\
Physical activities should be accompanied by a healthy diet & 4.10 & .9990 & positive \\
The daily practice of physical activities is very important to me as a woman & 4.06 & 1.069 & positive \\
I prefer group physical activities that involve my friends & 3.88 & 1.221 & positive \\
Exercising sports helps me to interact socially and build a successful relationships & 3.87 & 1.129 & positive \\
\hline
\end{tabular}


Table 3 shows that Saudi women support positively the idea of providing women's sport clubs, and also the idea of incorporating physical activities within girl schools regardless the high controversy in the local newspapers and social media to repel any attempt in this regard. Obviously, Saudi women realize and respect the social dimension of practicing physical activities in groups which this can develop friendships and help build successful social relationships according to the sample's point of view with a mean of 3.87 .

Table 4. Attitudes towards sport activities to reach social, psychological and familial goals

\begin{tabular}{lccc}
\hline Items & Mean & SD & Tendency \\
\hline Women keen to accustom kids to exercise & 3.87 & 1.154 & Positive \\
The time I spend at home or in shopping can be exploited much better by healthy & 3.78 & 1.088 & Positive \\
sport activities & 3.76 & 1.209 & Positive \\
I prefer sport activities that woman can exercise by her own & 3.55 & 1.234 & Positive \\
Women's club keen to organize mass sport activities & 3.54 & 1.300 & Positive \\
I prefer the diverse sport activities that include a Competitive nature & 3.54 & 1.153 Positive \\
There is a lot of activities that make me relaxed better than sport activities & 3.52 & 1.101 & Positive \\
I interested in the issues that talk about sports & &
\end{tabular}

In the same way, Table 4 shows the cognitive awareness of the study sample of benefit gains from practicing physical activities by encouraging their children to consider sports as an important part of their lives, and their understanding of its competitive nature. However, the research team didn't find justification for the sample's attitude for the mean that state: There are several activities that make me relaxed better than physical activities. This item got a high approval with a mean of 3.54 and standard deviation of 1.153.

Table 5. Some problems related to practicing physical activities according to the study sample

\begin{tabular}{lccc}
\hline Items & Mean & SD & Tendency \\
\hline Women may be exposed to serious injuries during exercise & 2.73 & 1.101 & Negative \\
Women can invest their time in useful activities other than sports & 2.46 & 1.237 & Negative \\
Sport activities may lead women to neglect their children and housekeeping & 2.27 & 1.225 & Negative \\
Women's exercise of sports is considered a waste of their time and physical strength & 1.82 & 1.205 & Negative \\
Establishing Women's sports facilities is considered a waste of public money & 1.79 & 1.201 & Negative \\
\hline
\end{tabular}

Table 5 shows, the means that has been shown to the sample as possible problems which women may be exposed to during exercise with means less than 3. This item is negative in the sense that the sample doesn't agree on it. This confirms the positivity of the overall attitude of the sample towards practicing physical activities. The sample doesn't consider practicing physical activities makes women neglect their children and home or consider it waste of public budget.

\section{Hypotheses Testing}

The first hypothesis states there are no significant statistical differences at $\alpha \leq 0.05$ in Saudi women's attitudes towards practicing physical activities based on the province of resident. The one way Analysis of variance (ANOVA) was used to test this hypothesis Table 6 shows the results of this test.

Table 6. ANOVA and Scheffe tests of dimensional comparisons for the differences in Saudi woman's attitudes towards sport activities based on the provinces of residents

\begin{tabular}{|c|c|c|c|c|c|c|c|c|c|}
\hline Province & Mean & SD & $F$ & Sig. & $\mathrm{CP}$ & EP & WP & NP & SP \\
\hline $\mathrm{CP}$ & 3.75 & .411 & 7.234 & $0.000 *$ & & $*$ & & & \\
\hline EP & 3.53 & .415 & & & & & & & $*$ \\
\hline WP & 3.73 & .471 & & & & & & & \\
\hline NP & 3.70 & .570 & & & & & & & \\
\hline SP & 3.83 & .382 & & & & & & & \\
\hline
\end{tabular}

$\mathrm{CP}$ : central province, EP: east province, WP: west province, NP: north province, SP: south province. ${ }^{*} \mathrm{p} \leq 0.05$ 
On the basis of results in Table 6, there are significant statistical differences in Saudi women's attitudes towards practicing physical activities based on the provinces of residents. However, Scheffe results indicated that these differences were between women from the eastern provinces and those from the central and southern provinces. The attitudes of Saudi women living in the eastern province were less than the attitudes of those living in the central and southern provinces. Therefore, this hypothesis was rejected and the alternative one states that there are significant statistical differences in Saudi women's attitudes towards practicing physical activities based on the provinces of residents was accepted.

The second hypothesis states that there are no significant statistical differences at $\alpha \leq 0.05$ in Saudi women's attitudes towards practicing physical activities based on age group. ANOVA test was used in order to test this hypothesis, and Table 7 shows the results.

Table 7. ANOVA and Scheffe tests of dimensional comparisons for the differences in Saudi woman's attitudes towards sport activities based on age

\begin{tabular}{llllllllll}
\hline Age & Mean & SD & F & Sig. & $18-25$ & $26-33$ & $34-41$ & $42-51$ & 52 and over \\
\hline $18-25$ & 3.76 & .416 & 15 & $0.000^{*}$ & & & & & \\
$26-33$ & 3.76 & .377 & & & & & & & \\
$34-41$ & 3.92 & .380 & & & & & & & \\
$42-51$ & 3.54 & .512 & & & & & & & \\
52 and over & 3.25 & .245 & & & & & & & \\
\hline$* \mathrm{p} \leq 0.05$ & & & & & & &
\end{tabular}

$* \mathrm{p} \leq 0.05$

Table 7 confirmed the statistically significant differences in Saudi women's attitudes towards practicing physical activities based on age $(\mathrm{F}=15, \mathrm{P}=0.000)$. Scheffe test results indicate that these differences were between women who aged 33 or less and 34 or more. The attitude of Saudi women' where higher among women who aged 33 or less in comparison with those who aged 34 or more. Therefore, this hypothesis was rejected to accept the alternative one that presumed that there are statistically significant differences in Saudi women's attitudes towards practicing physical activities based on age group.

The third hypothesis postulated that there are no statistically significant differences at $\alpha \leq 0.05$ in Saudi women's attitudes towards practicing physical activities based on weight. ANOVA test was used in order to test this hypothesis, and Table 8 shows the results.

Table 8. ANOVA and Scheffe tests of dimensional comparisons for the differences in Saudi woman's attitudes towards sport activities based on weight

\begin{tabular}{|c|c|c|c|c|c|c|c|c|c|c|c|}
\hline Approximate Weight & Mean & SD & $\mathrm{F}$ & Sig. & 1 & 2 & 3 & 4 & 5 & 6 & 7 \\
\hline 1 & 3.74 & .433 & 3.33 & $0.000^{*}$ & & & & & & & \\
\hline 2 & 3.75 & .386 & & & & & & & & & \\
\hline 3 & 3.80 & .390 & & & & & & & & & \\
\hline 4 & 3.65 & .492 & & & & & & & & $*$ & \\
\hline 5 & 3.78 & .455 & & & & & & & & & \\
\hline 6 & 3.83 & .401 & & & & & & & & & * \\
\hline 7 & 3.65 & .356 & & & & & & & & & \\
\hline
\end{tabular}

1: 45-50, 2: 51-56, 3:57-62, 4: 63-68, 5: 69-74, 6: 75-79, 7: 80 or over. ${ }^{*} \mathrm{p} \leq 0.05$

The results shown in Table 8 asserted the existence of statistically significant differences in Saudi women's attitudes towards practicing physical activities based on weight $(\mathrm{F}=3.33, \mathrm{P}=0.000)$. Scheffe test's indicated that these differences were between women who weigh $75-79 \mathrm{~kg}$ and those who weigh $63-68 \mathrm{~kg}$ and $80 \mathrm{~kg}$ or over. The attitudes of Saudi women' where higher among women who weigh $75-79 \mathrm{~kg}$. Therefore, the study hypothesis was rejected to accept the alternative one that suggested that there are statistical significant differences in Saudi women's attitudes towards practicing physical activities based on weight. ANOVA test was used in order to test this hypothesis, and Table 9 shows the results. 
Table 9. ANOVA and Scheffe tests of dimensional comparisons for the differences in Saudi woman's attitudes towards sport activities based on the educational level

\begin{tabular}{|c|c|c|c|c|c|c|c|c|c|c|c|c|}
\hline EDL & Mean & SD & $\mathrm{F}$ & Sig. & $\mathrm{NE}$ & RNW & $\mathrm{P}$ & I & S & B & $\mathrm{M}$ & $\mathrm{PhD}$ \\
\hline NE & 3.07 & 189 & 4.805 & $0.000 *$ & & & & & & $*$ & & \\
\hline RNW & 3.67 & .415 & & & & & & & & & & \\
\hline $\mathrm{P}$ & 3.52 & .497 & & & & & & & & & & \\
\hline I & 3.34 & .000 & & & & & & & & & & \\
\hline $\mathrm{S}$ & 3.70 & .420 & & & & & & & & & & \\
\hline B & 3.78 & .419 & & & & & & & & & & \\
\hline M & 3.70 & .319 & & & & & & & & & & \\
\hline $\mathrm{PhD}$ & 4.03 & .000 & & & & & & & & & & \\
\hline
\end{tabular}

EDL: education level, NE: not educated, RNW: read and but not write, P: primary, I: intermediate, S: secondary, B: bachelor, M: master. ${ }^{*} \mathrm{p} \leq 0.05$

The results shown in Table 9 indicated that there are statistically significant differences $\alpha \leq 0.05$ in Saudi women's attitudes towards practicing physical activities based on the educational level $(\mathrm{F}=4.805, \mathrm{P}=0.000)$. Scheffe test results indicated that these differences were between women who earned bachelor degree and the uneducated women, the attitudes of Saudi women where higher among women who earned bachelor degree. Hence, the hypothesis was rejected to accept the alternative one that there are statistical significant differences in Saudi women's attitudes towards practicing physical activities based on the educational level.

The fifth hypothesis presumed that there are no statistical significant differences at $\alpha \leq 0.05$ in Saudi women's attitudes towards practicing physical activities based on the nature of profession. ANOVA test was used in order to test this hypothesis, and Table 10 shows the results.

Table 10 indicated that there are statistically significant differences at $\alpha \leq 0.05$ in Saudi women's attitudes towards practicing physical activities based on the nature of the profession, $(\mathrm{F}=6.496, \mathrm{P}=0.000)$. Scheffe test results indicated that these differences were between the housewives and women who work in other jobs and between teachers, where the attitudes of the teachers where higher. Therefore, the study hypothesis was rejected to accept an alternative one that there are statistically significant differences in Saudi women's attitudes towards practicing physical activities based on the nature of profession.

Table 10. ANOVA and Scheffe tests of dimensional comparisons for the differences in Saudi woman's attitudes towards sport activities based on the nature of profession

\begin{tabular}{cccccccccc}
\hline Profession & Mean & SD & F & Sig. & HW & TE & AD & PR & OT \\
\hline HW & 3.63 & .383 & 6.496 & $0.000^{*}$ & & $*$ & & & $*$ \\
TE & 3.85 & .390 & & & & & & & \\
AD & 3.81 & .426 & & & & & & \\
PR & 3.76 & .414 & & & & & & \\
OT & 3.72 & .430 & & & & & & \\
\hline
\end{tabular}

HW: housewife, TE: teacher, AD: administrator, PR: professional. OT: other. * $\mathrm{p} \leq 0.05$

The sixth hypothesis suggested that there are no statistically significant differences at $\alpha \leq 0.05$ in Saudi women's attitudes towards practicing physical activities based on marital status. ANOVA test was used in order to test this hypothesis, and Table 11 shows the results.

The results in Table 11 indicated that there are no statistically significant statistical differences in Saudi women's attitudes towards practicing physical activities based on marital status $(\mathrm{F}=2.014, \mathrm{P}=0.110)$. Therefore, the hypothesis was accepted. 
Table 11. ANOVA of dimensional comparisons for the differences in Saudi woman's attitudes towards sport activities based on marital status

\begin{tabular}{ccccc}
\hline Marital Status & Mean & SD & F & Sig. \\
\hline Single & 3.76 & .423 & 2.014 & 0.110 \\
Married & 3.74 & .419 & & \\
Divorced & 3.72 & .429 & & \\
Widow & 3.36 & .132 & & \\
\hline
\end{tabular}

\section{Discussion and Conclusion}

The aim of the present study was to investigate Saudi women's attitudes toward physical activity. Six hypotheses were proposed in order to investigate these attitudes towards physical activity among Saudi women. The hypotheses were related to differences between attitudes in favor of residence, age, weight, educational level, profession and marital status. The results indicated that Saudi women in general would like to practice physical activities if they had the opportunity and suitable place, since they positively support the idea of providing women's sport clubs, and the idea of incorporating physical activities within girl schools. Obviously, Saudi women realize and respect that practicing physical activities in groups help building successful social relationships. In the same way, the results confirmed the cognitive awareness of participants in regard to benefits physical activities as they encourage their children to consider sports as an important part of their lives. However, the research team didn't find justification for the sample's attitude for the item related to subjects' viewpoint that there are several activities that make them relaxed better than physical activities. In relation to study hypotheses, the findings revealed that there are statistically differences in Saudi women's attitudes toward practicing physical activities that can be attributed to provinces of residents, age, weight, educational level and the nature of the profession. On the other hand, there are no statistically significant differences in Saudi women's attitudes towards practicing physical activities in favor of their marital status. Similar results were reached in previous results. In their study on physical activity and health beliefs among Saudi women, Al-Eisa and Al-Sobayel (2012) found a high level of physical activity among Saudi women. Concerning pace of residence, Al-Nuaim (2012) found significant differences in the physical activity levels of youth with regard to gender and geographical areas. According to Al-Nozha et al. (2007), the highest prevalence level of physical inactivity was highest in the central region of KSA in comparison with the southern region. Additionally, they stated that the prevalence of physical inactivity level among Saudis was increased in parallel with increasing age. As for educational level, it was concluded by Al-Hazzaa (2007) that there was no significant relationship between physical activity and educational levels of Saudi males and females. In relation to marital status, Khalaf et al. (2013) indicated that married participants have higher levels of physical activity. The results of Al-Nozha et al. (2007) revealed that level of physical activity prevalence among Saudis was lower for single than married participants. On the basis of these findings, the study concluded that there are numerous factors that play a critical role in practicing physical activity by Saudi women; i.e. place of residence, age, weight, educational level, and the nature of the profession.

\section{Study Limitations and Future Research}

The most important limitation of this study was the large size of the sample. It consisted of 1233 females from different regions in KSA. As many previous studies indicated, there were significant relationship between physical activity and numerous chronic diseases along with the findings of the current study related to differences among Saudi women in favor of various variables such as place of residence, age, educational level, nature of the profession, and weight; a future research may examine the mediation role of demographic characteristics in the relationship between physical activity and chronic disease.

\section{Acknowledgments}

This research project was supported by a grant from The Research Center for the Humanities, Deanship of Scientific Research at King Saud University, Riyadh, Saudi Arabia.

\section{References}

Al-Baker, F., Al-Haramlah, A., \& Mreza, H. (2013). Saudi women's attitudes towards sports activities and early intervention strategies to reduce the health consequences. A research presented to the scientific conference XIII of the science of sports psychology, the International Society of Sports Psychology ISSP, Beijing, China. 
Al-Baker, F., Al-Haramlah, A., \& Mreza, H. (2016). Relationship between Physical Activities of Women and the Prevalence of Some Common Diseases: Empirical Evidence from Saudi Arabia, Advances in Physical Education, 6, 67-75. http://dx.doi.org/10.4236/ape.2016.62008

Alburquerque-Sendín, F, Barberio-Mariano, E., Brandão-Santana, N., Rebelatto, D. A., \& Rebelatto, J R. (2012). Effects of an adapted physical activity program on the physical condition of elderly women: an analysis of efficiency. Revista Brasileira de Fisioterpia, 16(4), 328-336. http://dx.doi.org/10.1590/s1413-3555201200 5000025

Al-Haramlah, A.; Al-Bakr, F., \& Merza, H. (2015). Common Diseases and Some Demographic Characteristics among Saudi Women, International Education Studies, 8(12), 95-107. http://dx.doi.org/10.5539/ies.v8n12 p94

Al-Hazzaa, H. (2004). The public health burden of physical inactivity in Saudi Arabia. Journal of Family Community Medicine, 11(2), 45-51.

Al-Hazzaa, H. M. (2004). Prevalence of physical inactivity in Saudi Arabia: a brief review. Eastern Mediterranean Health Journal, 10(4-5), 663-670.

Al-Hazzaa, H. M. (2007). Health-enhancing physical activity among Saudi adults using the International Physical Activity Questionnaire (IPAQ). Public Health Nutrition, 10(1), 59-64. http://dx.doi.org/10.1017/ S1368980007184299

Al-Nozha, M. M., Al-Hazzaa, H. M., Arafah, M. R., Al-Khadra, A., Al-Mazrou, Y. Y., Al-Maatouq, M. A., ... Al-Shahid, M. S. (2007). Prevalence of physical activity and inactivity among Saudis aged 30-70 years. A population-based cross-sectional study. Saudi Medical Journal, 28(4), 559-68.

Al-Nozha, M., Al-Hazzaa, H., Arafah, M., Al-Khadra, A., Al-Mazrou, Y., Al-Maatouq, M., ... Al-Shahid, M. (2007). Prevalence of physical activity and inactivity among Saudis aged 30-70 years. A population-based cross-sectional study. Saudi Med J., 28(4), 559-568.

Al-Nuaim, A., Al-Nakeeb, Y., Lyons, M., Al-Hazzaa, H., Nevill, A., Collins, P., \& Duncan, M. (2012). The prevalence of physical activity and sedentary behaviours relative to obesity among adolescents from Al-Ahsa, Saudi Arabia: Rural versus urban variations. Journal of Nutrition and Metabolism, 2012(417589), 1-9. http://dx.doi.org/10.1155/2012/417589

Azevedo, M. R., Araújo, C. L., Reichert, F. F., Siqueira, F. V., da Silva, M. C., \& Hallal, P. C. (2007). Gender differences in leisure-time physical activity. International of Journal of Public Health, 52(1), 8-15. http://dx.doi.org/10.1007/s00038-006-5062-1

Berger, G., \& Peerson, A. 2009). Giving young Emirati women a voice: participatory action research on physical activity. Health Place, 15(1), 117-124. http://dx.doi.org/10.1016/j.healthplace.2008.03.003

Bull, F. C., \& Bauman, A. E. (2011). Physical inactivity: The "Cinderella" risk factor for non-communicable disease prevention. Journal of Health Communication, 16, 13-26. http://dx.doi.org/10.1080/10810730.2 011.601226

Conroy, M. B., Cook, N. R., Manson, J. E., Buring, J. E., \& Lee, I. M. (2005). Past physical activity, current physical activity, and risk of coronary heart disease. Medicine and Science in Sports and Exercises, 37(8), 1251-1256. http://dx.doi.org/10.1249/01.mss.0000174882.60971.7f

Gómez, L., Mateus, J., \& Cabrera, G. (2004). Leisure-time physical activity among women in a neighborhood in Bogotá, Colombia: Prevalence and socio-demographic correlates. Cad. Saúde Pública, Rio de Janeiro, 20(4), 1103-1109. http://dx.doi.org/10.1590/S0102-311X2004000400026

Hayes, C., \& Kriska, A. (2008). Role of physical activity in diabetes management and prevention. Journal of the American Dietetic Association, 108, 19-23. http://dx.doi.org/10.1016/j.jada.2008.01.016

Joy, E. A., \& Mottola, M. F., \& Chambliss, H. (2013). Integrating exercise is medicine $₫$ into the care of pregnant women. Curr Sports Med Rep., 12(4), 245-247. http://dx.doi.org/10.1249/JSR.0b013e31829a6f7e

Khalaf, A., Ekblom, O., Kowalski, J., Berggren, V., Westergren, A., \& Al-Hazzaa, H. (2013). Female University Students' Physical Activity Levels and Associated Factors: A cross-sectional study in southwestern Saudi Arabia. International Journal of Environmental Research Public Health, 10(8), 3502-3517. http://dx.doi.org/10.3390/ijerph10083502

Khalaf, A., Ekblom, Ö., Kowalski, J., Berggren, V., Westergren, A., \& Al-Hazzaa, H. (2013). Female university students' physical activity levels and associated factors--a cross-sectional study in southwestern Saudi Arabia. 
International, 10(8), 3502-3517. http://dx.doi.org/10.3390/ijerph10083502

Madanat, H., \& Merrill, R. M. (2006). Motivational factors and stages of change for physical activity among college students in Amman, Jordan. Promotion and Education, 13(3), 185-90.

Martorell, R., Kettel, L., Khan, K., Hughes, M., \& Grummer-Strawn, M. (2000). Obesity in women from developing countries. European Journal of Clinical Nutrition, 54, 247-252. http://dx.doi.org/10.1038/sj. ejen.1600931

Musaiger, A. O., Al Hazzaa, H. M., Al-Qahtani, A., Elati, J., Ramadan, J., Aboulella, N. A., Mokhtar, N., \& Kilani, H. A. (2011). Strategy to combat obesity and to promote physical activity in Arab countries. Diabetes Metabolic Syndrome and Obesity: target and therapy, 4, 89-97. http://dx.doi.org/10.2147/DMSO.S17322

Ng, S. W., Zaghloul, S., Ali, H. I., Harrison, G., \& Popkin, B. M. (2011). The prevalence and trends of overweight, obesity and nutrition-related non-communicable diseases in the Arabian Gulf States. Obesity Review, 12(1), 1-13. http://dx.doi.org/10.1111/j.1467-789X.2010.00750.x

Päivi, M, Mirja, H., \& Terttu, P. (2010). Changes in Physical Activity Involvement and Attitude to Physical Activity in a 16-Year Follow-Up Study among the Elderly. Journal of Aging Research, 15(1), 22-45. http://dx.doi.org/10.4061/2010/174290

Ramadan, J., Vuori, I., Lankenau, B., Schmid, T., \& Pratt, M. (2010). Developing a national physical activity plan: the Kuwait example. Global Health Promotion, 17(2), 52-7. http://dx.doi.org/10.1177/1757975910365230

Senter, C, Appelle, N., \& Behera, S. K. (2013). Prescribing exercise for women. Curr Rev Musculoskeletal Med., 6(2), 164-72. http://dx.doi.org/10.1007/s12178-013-9163-1

Van Camp, C. M., \& Hayes, L. B. (2012). Assessing and increasing physical activity. Journal of Applied Behavior Anal, 45(4), 871-5.

Wolfenstetter, S. B, \& Wenig, C. M. (2010). Economic evaluation and transferability of physical activity programmers in primary prevention: A systematic review. Int J Environ Res Public Health, 7(4), 1622-48. http://dx.doi.org/10.3390/ijerph7041622

\section{Copyrights}

Copyright for this article is retained by the author(s), with first publication rights granted to the journal.

This is an open-access article distributed under the terms and conditions of the Creative Commons Attribution license (http://creativecommons.org/licenses/by/3.0/). 